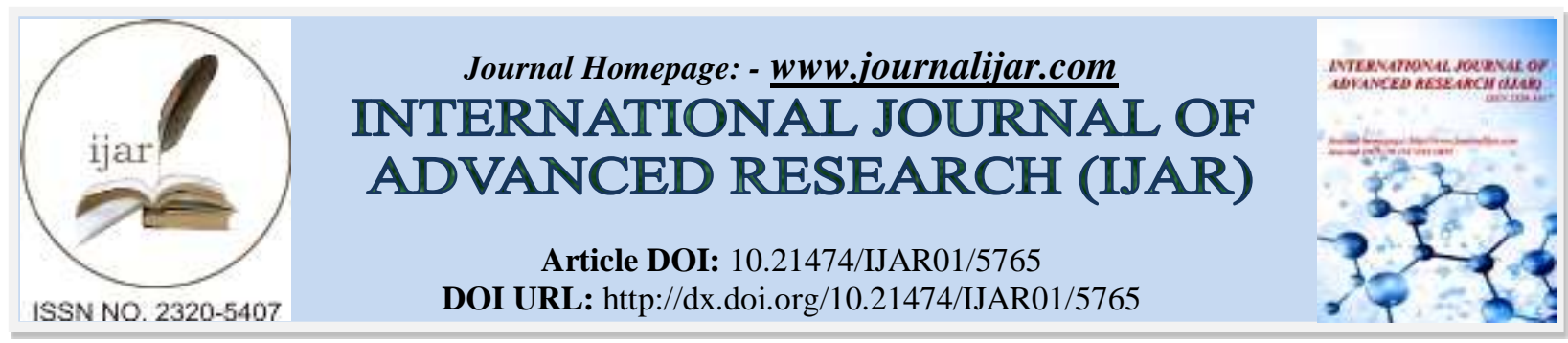

RESEARCH ARTICLE

\title{
EFFECT OF SEASONAL TEMPERATURE VARIATION ON THE DURATION OF LIFE CYCLE STAGES OF THE FLY OF FORENSIC IMPORTANCE, PARASARCOPHGA DUX (THOMSON) (DIPTERA: SARCOPHAGIDAE).
}

Shabnamnaz Siddiki and S. P. Zambare.

Department of Zoology, Dr. Bababsheb Ambedkar Marathwada University, Aurangabad, (M.S.) India.

\section{Manuscript Info}

(n.........................

Manuscript History

Received: 04 September 2017

Final Accepted: 06 October 2017

Published: November 2017

Key words:-

Forensic entomology, Parasarcophaga dux (Thomson), fluctuate temperature, life cycle duration, seasons.

\section{Abstract}

Sarcophagid flies belonging to carrion insect communities provide the information about the corps. Parasarcophaga dux (Thomson) (Diptera: Sarcophagidae) collected from Latur district of Maharashtra (India) has been studied for the duration of different life cycle stages in three different seasons i.e. rainy, winter and summer seasons under the room temperature. The female released $\mathrm{I}^{\text {st }}$ instar larvae which after two larval mounts undergo prepupation and then pupation in the soil. The adult emerged out from pupae.

During rainy season the life cycle duration from larvaeposite to emergence of adult was $315.15 \pm 3.28 \mathrm{hrs}$, during winter season in $359.56 \pm 2.44 \mathrm{hrs}$, while in summer season it took $265.51 \pm 6.28 \mathrm{hrs}$, under the fluctuating diurnal temperature and humidity of the laboratory.

The time durations of life cycle stages of $P$. dux in the different seasons can be used to determine the PMI using the meterological data and $P$. dux life cycle stages collected from the cadaver.

Copy Right, IJAR, 2017,. All rights reserved.

\section{Introduction:-}

The more than 2600 species [1] of flesh flies (Family - Sarcophagidae) reported belongs to 1000 genera all around the world. In India the family Sarcophagidae represents 117 species and 38 genera of three subfamilies. The genus Sarcophaga includes more than 22 recorded species belonging to 6 subgenera. Most flesh flies are parasites or predators with relatively small numbers of species with a true preference for vertebrate carrion [2-3]. Flesh flies are usually considered as a taxon of high forensic importance [4-5]. However their participation in carrion insect community was tasted almost exclusively in experiments with small sized carrion [6-11].

Sarcophagidae are considered to be unimpeded by rain and to fly despite the weather [12]. The females deposit the larvae in the safe nutritious location [13]. As a result flesh flies may be the initial colonizers of the body outdoors, if there is long period of rainy weather. Despite this, many flesh flies prefer sunlight rather than shaded condition [4] although Sarcophaga (Subgenus - Robineauella) caerulescens is considered a shade lover [14].

The time taken by Sarcophaga larvae to emerge as an adult is considered to be between $8-15$ days [15]. Kamal (1958) provide an indications of life cycle duration of various stages of American Sarcophagid species. Development time to adult emergence varied by as much as 252 hours [16] depending on the temperature. 
Therefore, this provides a source of variation and limitations in the use of this species to calculate the time since death.

The present research work was carried in the laboratory in Latur district, Maharashtra, India to study the time duration of different stages of the life cycle of Parasarcophga dux (Thomson) in different seasons.

\section{Material and method:-}

The maggots were collected from dead dog from Latur district (MS), India and were reared in laboratory in rearing chamber on fresh chopped buffalow liver and sugar syrup on cotton. These chambers were covered with a fine muslin cloth in order to facilitate fresh air and to prevent the entry of parasites. These chambers were maintained under natural temperature and humidity condition. Soil was also supplied for pupation. The maggots were observed throughout their developmental stages at different time interval on hourly basis. After adult emergence the flesh flies were identified and were to be $P$. $d u x$ and some Calliphorids. Adult male and female $P$. $d u x$ were maintained in insect cages with fresh liver every day. The $\mathrm{I}^{\text {st }}$ instar larvae released on liver were monitored on hourly basis to find the duration with reporting of temperature. This experiment was repeated in three times in three different seasons i.e. rainy season, winter season and summer season.

\section{Observation and result:-}

In the present study the life cycle stages of Parasarcophga dux (Thomson) are larvae (i.e. I $^{\text {st }}$ instar, II $^{\text {nd }}$ instar and III $^{\text {rd }}$ instar), pre-pupa, pupa and adult. The female releases the $\mathrm{I}^{\text {st }}$ instar larvae directly on the liver. The duration of life cycle stages changed as per the temperature variations in different seasons.

\section{Rainy season:}

In rainy season it has been observed that the time duration of different life cycle stages of Parasarcophga dux (Thomson) was completed in $315.15 \pm 3.28$ hours from larviposite up to emergence of adult fly at the average temperature ranging from $23-26.7^{\circ} \mathrm{C}$ and average humidity ranging from $28.5-58.6 \%$. It was observed that the time duration of different life cycle stages of Parasarcophga dux (Thomson) was $25.10 \pm 1.13$ hours, $27.45 \pm 1.22$ hours, $43.28 \pm 5.25$ hours, $23.47 \pm 3.10$ hours and 195.05 \pm 6.39 hours for ${ }^{\text {st }}$ instar, II $^{\text {nd }}$ instar, III $^{\text {rd }}$ instar, pre-pupa and pupa respectively (Table 1).

Table 1:- Time duration of different life cycle stages of Parasarcophaga dux (Thomson) during rainy season

\begin{tabular}{|l|l|l|l|l|}
\hline \multicolumn{2}{|l|}{ life stages } & PMI (H:MM) & Average temperature $\left({ }^{\mathbf{0}} \mathbf{C}\right)$ & Average humidity (\%) \\
\hline \multirow{3}{*}{ Larva } & $\mathrm{I}^{\text {st }}$ instar & $25: 10 \pm 1: 13$ & $25.5 \pm 1.1$ & $33.5 \pm 1.1$ \\
\cline { 2 - 5 } & $\mathrm{II}^{\text {nd }}$ instar & $27: 45 \pm 1: 22$ & $26 \pm 1.04$ & $28.5 \pm 2.1$ \\
\cline { 2 - 5 } & $\mathrm{III}^{\text {rd }}$ instar & $43: 28 \pm 5: 25$ & $26.7 \pm 0.7$ & $41.1 \pm 1.3$ \\
\hline Pre-pupa & $23: 47 \pm 3: 10$ & $23 \pm 0.9$ & $51.5 \pm 1.03$ \\
\hline Pupa & $195: 05 \pm 6: 39$ & $23.4 \pm 1.2$ & $58.6 \pm 1.4$ \\
\hline Total duration & $315: 15 \pm 3: 28$ & & \\
\hline
\end{tabular}

( \pm indicates standard deviation of three values)

2. Winter season:

In winter season the time duration of different life cycle stages of Parasarcophga dux (Thomson) was completed in $359.56 \pm 2.44$ hours from larviposite to emergence of adult fly at the average temperature ranging from $18-22.7{ }^{\circ} \mathrm{C}$ and average humidity ranging from $44-68.8 \%$. The time duration of different life cycle stages of Parasarcophga $d u x$ (Thomson) was $26.50 \pm 2.04$ hours, $28 \pm 4.12$ hours, $45.55 \pm 3.21$ hours, $24.05 \pm 2.19$ hours and $235.06 \pm 3.02$ hours of $\mathrm{I}^{\text {st }}$ instar, II $^{\text {nd }}$ instar, III $^{\text {rd }}$ instar, pre-pupa and pupa respectively (Table 2).

Table 2:- Time duration of different life cycle stages of Parasarcophaga dux (Thomson) during winter season

\begin{tabular}{|l|l|l|l|l|}
\hline \multicolumn{2}{|l|}{ life stages } & PMI (H:MM) & Average temperature $\left({ }^{\mathbf{0}} \mathbf{C}\right)$ & Average humidity (\%) \\
\hline \multirow{3}{*}{ Larva } & $\mathrm{I}^{\text {st }}$ instar & $26: 50 \pm 2: 05$ & $18.5 \pm 1.7$ & $68.8 \pm 1.1$ \\
\cline { 2 - 5 } & II $^{\text {nd }}$ instar & $28: 00 \pm 4: 12$ & $18 \pm 1.4$ & $62 \pm 0.4$ \\
\cline { 2 - 5 } & III $^{\text {rd }}$ instar & $45: 55 \pm 3: 21$ & $22.7 \pm 2.2$ & $51.7 \pm 0.2$ \\
\hline Pre-pupa & $24: 05 \pm 2: 19$ & $20.5 \pm 1.5$ & $66.5 \pm 0.2$ \\
\hline Pupa & $235: 06 \pm 3: 02$ & $20.3 \pm 1.8$ & $44 \pm 1.2$ \\
\hline Total duration & $359: 56 \pm 2: 44$ & & \\
\hline
\end{tabular}


( \pm indicates standard deviation of three values)

3. Summer season:

In summer season, the time duration of different life cycle stages of Parasarcophga dux (Thomson) was completed $260.51 \pm 6.28$ hours from the larviposite to emergence of adult fly at the average temperature ranging from 31.5 to $33.7^{\circ} \mathrm{C}$ and average humidity $13.6-20.5 \%$. The time duration of different lifecycle stages of Parasarcophga dux was $22.51 \pm 1.52$ hours, $24.30 \pm 1.71$ hours, $26.45 \pm 4.43$ hours, $18.39 \pm 2.52$ hours and $16806 \pm 2.17$ hours of I $^{\text {st }}$ instar, II $^{\text {nd }}$ instar, III $^{\text {rd }}$ instar, pre-pupa and pupa respectively (Table 3 )

Table 3:- Time duration of different life cycle stages of Parasarcophaga dux (Thomson) during summer season

\begin{tabular}{|l|l|l|l|l|}
\hline \multicolumn{2}{l|}{ life stages } & PMI (H:MM) & Average temperature $\left({ }^{\mathbf{0}} \mathbf{C}\right)$ & Average humidity (\%) \\
\hline \multirow{3}{*}{ Larva } & $\mathrm{I}^{\text {st }}$ instar & $22: 51 \pm 1: 52$ & $31.5 \pm 0.8$ & $13.6 \pm 0.4$ \\
\cline { 2 - 5 } & II $^{\text {nd }}$ instar & $24: 30 \pm 1: 17$ & $31.7 \pm 1.1$ & $14.5 \pm 0.3$ \\
\cline { 2 - 5 } & III $^{\text {Id }}$ instar & $26: 45 \pm 4: 48$ & $31.6 \pm 1.1$ & $18.7 \pm 1.1$ \\
\hline Pre-pupa & $18: 39 \pm 2: 52$ & $33 \pm 0.5$ & $20.5 \pm 0.5$ \\
\hline Pupa & $168: 06 \pm 2: 17$ & $33.7 \pm 0.7$ & $17.7 \pm 0.7$ \\
\hline Total duration & $260: 51 \pm 6: 28$ & & \\
\hline
\end{tabular}

( \pm indicates standard deviation of three values)

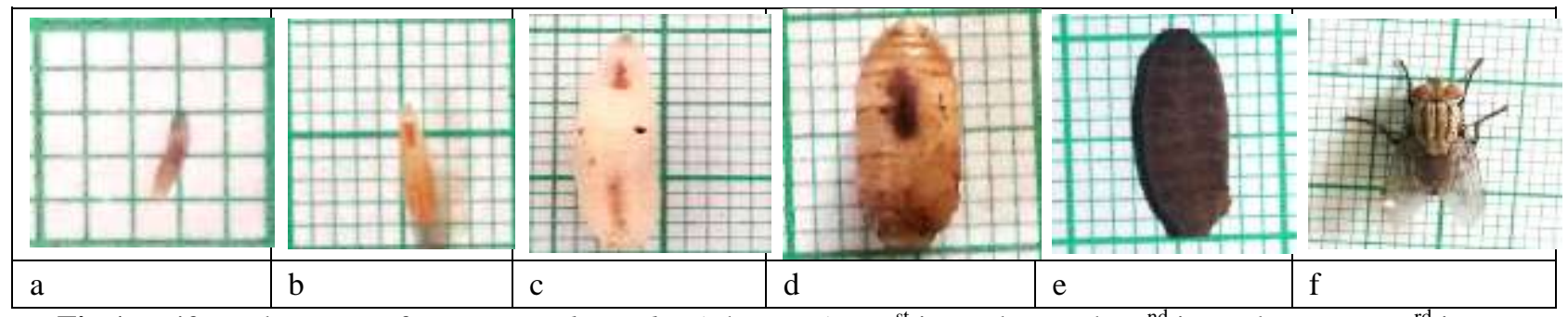

Fig.1:- Life cycle stages of Parasarcophaga dux (Thomson). a. It $^{\text {st }}$ instar larvae; b. II ${ }^{\text {nd }}$ instar larvae; c. III $^{\text {rd }}$ instar larvae; d. Pre-pupa; e. Pupa; f. Adult fly.

\section{Discussion:-}

Species of flesh flies larvae are very similar in appearance and traditionally have been difficult to identify [4]. Therefore accurate identification of either larvae or adults has had to be made by taxonomic specialists [17]. Taxonomically $P$. dux has been confused with Parasarcophaga misera by many previous authors [4], but more recent research has a clarified classification of these two species as distinct species and separated them based on adult males [18-20].

It was observed that at higher temperature and humidity the maggots emerged faster than lower temperature and higher humidity and increase in temperature will increase the rate of metabolism [21]. An earlier study done on $P$. terraenovae it was found that fluctuating temperature actually lade to significant faster rate of development [22]. In present study it was observed that III $^{\text {rd }}$ instar larvae took higher time period than $\mathrm{I}^{\text {st }}$ and II $^{\text {nd }}$ instar larvae. It was also recorded that $\mathrm{II}^{\text {nd }}$ and $\mathrm{III}^{\text {rd }}$ instars took prolonged time for development as compare to first instar larvae [23-24].

The time taken by Sarcophaga (Subgenus Robineaulla) caerulescens larvae to emerge as an adult is considered to be between 8-12 days [15]. An indication was also provided on the lifecycle duration of various stages of the American Sarcophagid species [25]. However different observations have been reported for the developmental rates of the $S$. $d u x$. Life cycle of Sarcophaga dux from the first instar to the adult was $312.0 \pm 3.0 \mathrm{~h}$ under uncontrolled indoor temperature in Malaysia [26]. Report from study in north Thailand in the year 2002-2003 under natural temperature indicates seasonal variation in development of fly with rapid larval development in summer at around 72 hrs, while it took 72-96 hrs.in rainy season and $96 \mathrm{hrs}$.in winter [27-28]. The life cycle of Sarcophaga cultellata at $25^{\circ} \mathrm{C}$ and $50 \%$ humidity showed a total development time from larvae position to first adult emergence was $330 \pm 12 \mathrm{hr}$ [29]. The only report from India on the development of larvae of Sarcophaga $(L)$ tibialis raised on chicken liver indicated maximum development between $15-30^{\circ} \mathrm{C}$ [30-35]. 
The present results are similar with the developmental duration of Chrysomya megacephala (Diptera: Calliphoridae), in rainy season and low constant temperature of $10^{\circ} \mathrm{C}$ and humidity $19 \%$, the total life cycle duration in rainy season was completed in $265 \mathrm{~h} \pm 2 \mathrm{~h}(11.04$ days \pm 0.08 days $)$ when the temperature ranged between $26^{\circ} \mathrm{Cand} 29^{\circ} \mathrm{C}$ and humidity ranged between $35 \%$ and $50 \%$, while in the low constant temperature $10^{\circ} \mathrm{C} \pm 0.5^{\circ} \mathrm{C}$ the life cycle was completed in $609 \mathrm{~h} \pm 4 \mathrm{~h}$ (25.38 days \pm 0.16 days) indicating a delay in the life cycle by14.37 days \pm 0.13 days [36]. Similarly our current results are in agreement with another study on the effect of different temperature and humidity on the lifecycle duration and morphological parameters of Chrysomya rufifacies (Diptera: Calliphoridae) in different seasons It was reported that the life cycle of Chrysomya rufifacies in summer was completed in $241 \pm 2.17 \mathrm{~h}(10.04$ days \pm 0.12 days $)$ when the temperature ranged between $30.1^{\circ} \mathrm{C}$ and $37.2^{\circ} \mathrm{C}$, but in the rainy season it was completed in $275 \mathrm{~h} \pm 2.27 \mathrm{~h}$ (11.46 days \pm 0.45 days), when the temperature ranged between $26.2^{\circ} \mathrm{C}$ and $30.1^{\circ} \mathrm{C}$, while in winter the life cycle was completed in $318 \mathrm{~h} \pm 2.45 \mathrm{~h}$ (13.25 days \pm 0.25 days) when the temperatures ranged between $26.4^{\circ} \mathrm{C}$ and $18.2^{\circ} \mathrm{C}$ respectively [37].

In previous study in laboratory, at the fluctuating temperature during rainy season, winter season and summer season, Chrysomya megacephala took 237 hours 47 minutes, 263 hours 51 minutes and 211 hours 13 minutes respectively. Whereas the Chrysomya rufifacies took 239 hours 14 minutes, 286 hours 02 minutes and 216 hours 26 minutes during rainy season, winter season and summer season respectively [38].

\section{Conclusion:-}

It is observed that developmental time of different stages of life cycle of Parasarcophga dux from larviposite to emergence of adult differ in various seasons. On the basis of result it was clearly seen that a changes in temperature and humidity bring about a significant changes in developmental rate of the larval stages. In the condition with the higher temperature, larvae developed quickly and matured into pupa as compared to that grown in cooler temperature.

\section{Acknowledgement:-}

Authors are thankful to the Department of Zoology, Dr. Babasaheb Ambedkar Marathwada University, Aurangabad (MS), India for providing the laboratory facilities to carry out this research work.

\section{References:-}

1. Pape T (1996): Catalogue of the Sarcophagidae of the world (Insecta: Diptera). Mem Entomol Int 8:1-558

2. Povolny, D. and Verves, Y. (1997): The flesh-flies of Central Europe. Spixiana, Supplement 24, Munchen

3. Richet, R., Blackith R.M., Pape, T. (2011): Sarcophaga of France (Diptera:Sarcophagidae). Pensoft Series Faunistica, Sofia

4. Smith KGV (1986): A manual of forensic entomology. The Trustees of the British Museum, London.

5. Byrd, J.H. and Castner, J.L. (2009): Forensic Entomology: the utility of arthropods in legal investigations. CRC Press, Boca Raton.

6. Denno, R.F. and Cothran, W.R. (1976): Competitive interactions and ecological strategies of Sarcophagid and Calliphorid flies inhabiting rabbit carrion. Ann Entomol Soc Am 69(1):109-113

7. Hanski, I. (1976): Breeding experiments with carrion flies (Diptera) in natural conditions. Ann Entomol Fenn 42:113-121

8. Hanski, I. (1987): Carrion fly community dynamics: patchiness, seasonality and coexistence. Ecol Entomol 12:257-266. doi:10.1111/j.1365-2311.1987.tb01004.x

9. Hanski I, Kuusela S (1980): The structure of carrion fly communities: differences in breeding seasons. Ann Zool Fenn 17:185-190

10. Kuusela, S. andHanski, I. (1982): The structures of carrion fly communities: the size and the type of carrion. Ecography 5(4):337-348. doi:10.1111/j. 1600-0587.1982.tb01048.x

11. Blackith, R.E. and Blackith, R.M. (1990): Insect infestations of small corpses. J Nat Hist 24(3):699-709. doi:10.1080/00222939000770481

12. Erzinclioglu, Z. (2000): Maggots, murder and men: memories and reflections of forensic entomologists. Harley books, $256 \mathrm{pp}$.

13. Archer, M. S. and Elgar, M. A. (2003): Yearly activity pattern in southern Victoria (Australia) of seasonally active carrion insects. Forensic Science International 132 (3): 173-176.

14. Singh, D. and Bharti, M. (2008): Some notes on the nocturnal larviposition by two species of Sarcophaga (Diptera: Calliphoridae). Forensic Science International 177: 19-126. 
15. Pohjoismäki JL, Karhunen PJ, Goebeler S, Saukko P, Sääksjärvi IE (2010): Indoors forensic entomology: colonization of human remains in closed environments by specific species of sarcosaprophagous flies. Forensic SciInt 199(1):38-42. doi:10.1016/j.forsciint.2010.02.033

16. Byrd, J.H. and Bulter, J.E. (1998): Effect of temperature on Sarcophaga haemorrhoidalis (Diptera: Sarcophagidae) development. Journal of Medical Entomology 35: 694-698.

17. Zumpt, F., (1965): Myiasis in man and animal in the old world, Butterworths, London.

18. Sugiyama E, Shinonaga S, Kano R. (1988): Sarcophagine flies from Nepal with the description of a new species (Diptera: Sarcophagidae). Jpn J Sanit Zool.; 39:355-362.

19. Kano, R. and Shinonaga, S. (1994): Studies on the Sarcophagid flies from Nepal (Diptera: Sarcophagidae). Jap. J. Sanit. Zool., 45: 253-275.

20. Greenberg, B. and Kunich, J.C. (2002): Entomology and the law. Flies as forensic indicators. Cambridge University Press: Cambridge; pp 249-283.

21. Gomes, L., Gomes, G., Van ZCJ (2009): The influence of temperature on the behavior of burrowing in larvae of the blowflies, Chrysomya albiceps and Lucilia cuprina, under controlled conditions. J Insects Sci. 9: 14.

22. Davies, L. and Ratcliffe, G. (1994): Developmental rate of some pre-adult stages in blowfly with reference to low temperatures. Med. Vet. Entomol. 8:245-254.

23. Nabity, P.D., Higley, L.G., and Heng-Moss, T.M. (2006): Effect of temperature on development of Phormia regina (Diptera: Calliphoridae) and use of developmental data in determining time intervals in forensic entomology. Journal of Medical Entomology 43: 1276-1286.

24. Bharti, M., Singh, D. and Sharma, Y. P. (2007): Effect of temperature on the development of forensically important blowfly Chrysomya megacephala (Fab.) (Diptera: Calliphoridae) Entomon, 32(2): 149-151.

25. Kamal, A.S. (1958): Comparative study of thirteen species of Sarcosapropphagous Calliphoridae and Sarcophagidae (Diptera). Binomics. Annals of the Entomological Society of America. 51(3): 261-271. doi: 10.1093/aesa/51.3.261.

26. Jeffrey, D., Wells, and Joshua, L. and Smith (2013): First Report of Blaesoxiphaplin thopyga (Diptera: Sarcophagidae) from a Human Corpse in the U.S.A. and a New State Geographic Record Based on Specimen Genotype. J Forensic Sci.; 58(5): 1378-80.

27. Sukontason K, Sukontason KL, Piangjai S, Chaiwong T, Boonchu , Vogtsberger, R.C. (2003): Larval ultrastructure of Parasarcophaga dux (Thomson) (Diptera: Sarcophagidae). Micron. 34(8): 359-364.

28. BanzigerH, and Pape T. (2004): Flowers; Faeces and cadavers: natural feeding and laying habits of flesh flies in Thailand (Diptera: Sarcophagidae, Sarcophaga spp.). Journal of Natural History; 38:1677-1694.

29. Kumara TK, Hassan AA, Salmah MR, Bhupinder S. (2013): Larval growth of Liosarcophaga dux Thompson (Diptera: Sarcophagidae) under uncontrolled indoor temperatures in Malaysia. Southeast Asian J Trop Med Public Health; 44(2):182-7.

30. Sharma.R, and Mitra, B. (2014): Check-list of Indian flesh flies (Insecta: Diptera: Sarcophagidae). Zsigov in/checklist/Indian_Sarcophagidae pdf.

31. Sukontason, K.L., Sanit, S., Klong-klaew, T., Tomberlin, J.K. and Sukontason, K.(2014): Sarcophaga (Liosarcophaga) dux (Diptera: Sarcophagidae): A flesh fly species of medical importance. Biological Research.47: (14) 1-9.

32. Nandi, B.C. (2002): Fauna of India: Diptera: Sarcophagidae. Published by Zoological Survey of India. 10: 270274.

33. Heo, C.C., Latif, B.,Kurahashi, H., Nazni, W.A. and Omar,B. (2011): Oviposition of forensically important dipterans on a high-rise building, with a new host record of parasitoids in Malaysia (abstract), 9th Annual Conference of North American Forensic Entomology Association, College Station, Texas. Ref Type: Conference Proceeding.

34. Mercedes, D.D. and Hardy, D.E. (1977): A catalog of the Diptera of the Oriental region, Suborder Brachycera through Division Aschiza, Suborder Cyclorrahapha: The University Press of Hawaii, Honolulu Vol-II: 557-583.

35. Senior-White, R., Aubertin, D. and Smart, J. (1940): The fauna of British India, including the remainder of the Oriental region, Diptera. Family Calliphoridae. Vol. VI. London: Taylor and Francis 6 208-281.

36. Abd-AlGalil FM, Zambare SP (2015): Effect of temperature on development of Calliphorid fly of forensic importance Chrysomya megacephala (Fabricius, 1794). Indian J Appl Res 5: 767-769.

37. Abd-AlGalil FM, Zambare SP (2015a): Effect of temperature on development of Calliphorid flies of forensic importance, Chrysomya rufifacies (Macquart, 1842). IJAR: 1099-1103.

38. Siddiki S, Zambare SP (2017). Studies on time duration of life stages of Chrysomya megacephala and Chrysomya rufifacies (Diptera: Calliphoridae) during different seasons. J Forensic Res 8:379. doi:10.4172/2157-7145.1000379. 